\title{
Preliminary geochemical characterization of the Mts. Simbruini karst aquifer (Central Italy)
}

\author{
Marianna Cangemi ${ }^{1}$, Massimo Ranaldi ${ }^{2, *}$, Maria Luisa Carapezza ${ }^{2}$, Marco Vinci $^{3}$ and \\ Paolo Madonia $^{4}$ \\ (1) Dipartimento di Science della Terra e del Mare, Università degli Studi di Palermo, Palermo, Italy \\ (2) Istituto Nazionale di Geofisica e Vulcanologia, Sezione Roma 1, Roma, Italy \\ (3) GeoStudioVinci, Guidonia Montecelio, Roma, Italy \\ (4) Istituto Nazionale di Geofisica e Vulcanologia, Sezione Roma 2, Roma, Italy
}

Article history: received June 14, 2021; accepted October 4, 2021

\begin{abstract}
Mts. Simbruini karst aquifer feeds important springs whose capture contributes to the water supply of Rome City. To improve the geochemical characterization of this aquifer, we analyzed 36 groundwater samples, 29 from springs and 7 from shallow wells, collected in 1996 and 2019. Atomic adsorption spectroscopy, titration, ionic chromatography and mass spectrometry were the used analytical methods. Groundwater is bicarbonate alkaline-earth type and $\mathrm{HCO}_{3}{ }^{-}$dominance confirms that the aquifer is hosted in carbonate rocks. Total alkalinity vs. cations plot indicates that $\mathrm{CO}_{2}$ driven weathering controls the water chemistry. The probability plots of $\mathrm{HCO}_{3}{ }^{-}$, cations and $\mathrm{Ca}^{2+}$ $+\mathrm{Mg}^{2+}$ indicate four groundwater populations with the less represented one (9 samples) characterized by the highest $\mathrm{PCO}_{2}$ values ( $>0.3 \mathrm{~atm}$ ). Most anomalous values of the dissolved $\mathrm{PCO}_{2}$ are from springs located near the center of the studied area. Four samples have negative values of $\delta^{13} \mathrm{C}_{\mathrm{CO} 2}$ (about $-22 \%$ vs. $\mathrm{PDB}$ ), indicating its organic origin, but two other samples have positive values (1.6 and $2.6 \%$ vs. $\mathrm{PDB}$ ), similar to those observed in the $\mathrm{CO}_{2}$ of deep origin discharged at the close Colli Albani volcano. Therefore, geochemical evidence indicates that the Mts. Simbruini aquifer is locally affected by the input of deep originated $\mathrm{CO}_{2}$, likely rising up along fractures, interacting with a recharge of meteoric origin, as evidenced by its $\delta^{2} \mathrm{H}$ and $\delta^{18} \mathrm{O}$ isotopic signatures.
\end{abstract}

Keywords: Water resources; Groundwater processes; Chemistry of waters; Hydrological processes: interaction, transport, dynamics; Fluid Geochemistry.

\section{Introduction}

Because of the large diffusion worldwide of outcropping limestone rocks, karst aquifers are amongst the most important suppliers of drinkable water [Stevanovic, 2015]. Karst aquifers represent about the $40 \%$ of the supply of drinkable water in the Mediterranean in general, and in Italy in particular. The $90 \%$ of water distributed by the metropolitan aquifer of Rome is of karst origin [Società Speleologica Italiana, 2002].

Many of these are located in the Aniene river valley, between Mts. Simbruini and Mts. Ruffi (Figure 1). The main aquifer of the area is hosted within the Simbruini calcareous rocks, particularly where important karst phenomena 


\section{Marianna Cangemi et al.}

developed, increasing significantly the rock permeability [Vinci, 1998]. The hydrogeology of this area has been described in detail in the unpublished thesis of Vinci [1998], who reported also some chemical analyses of the groundwater, but without developing a detailed geochemical study, of great importance for the characterization and management of the huge aquifers of Mts. Simbruini. With the aim of completing and extending these first data, we carried out a more detailed geochemical study of the area, collecting and analyzing in May 2019 six new samples from springs and compared the results with the unpublished data collected in May 1996 [Vinci, 1998]. In doing this, we followed the same approach used by Madonia et al. [2020] for describing the characteristics of the main karst aquifer of Central Italy, of which study the present article represents the completion.

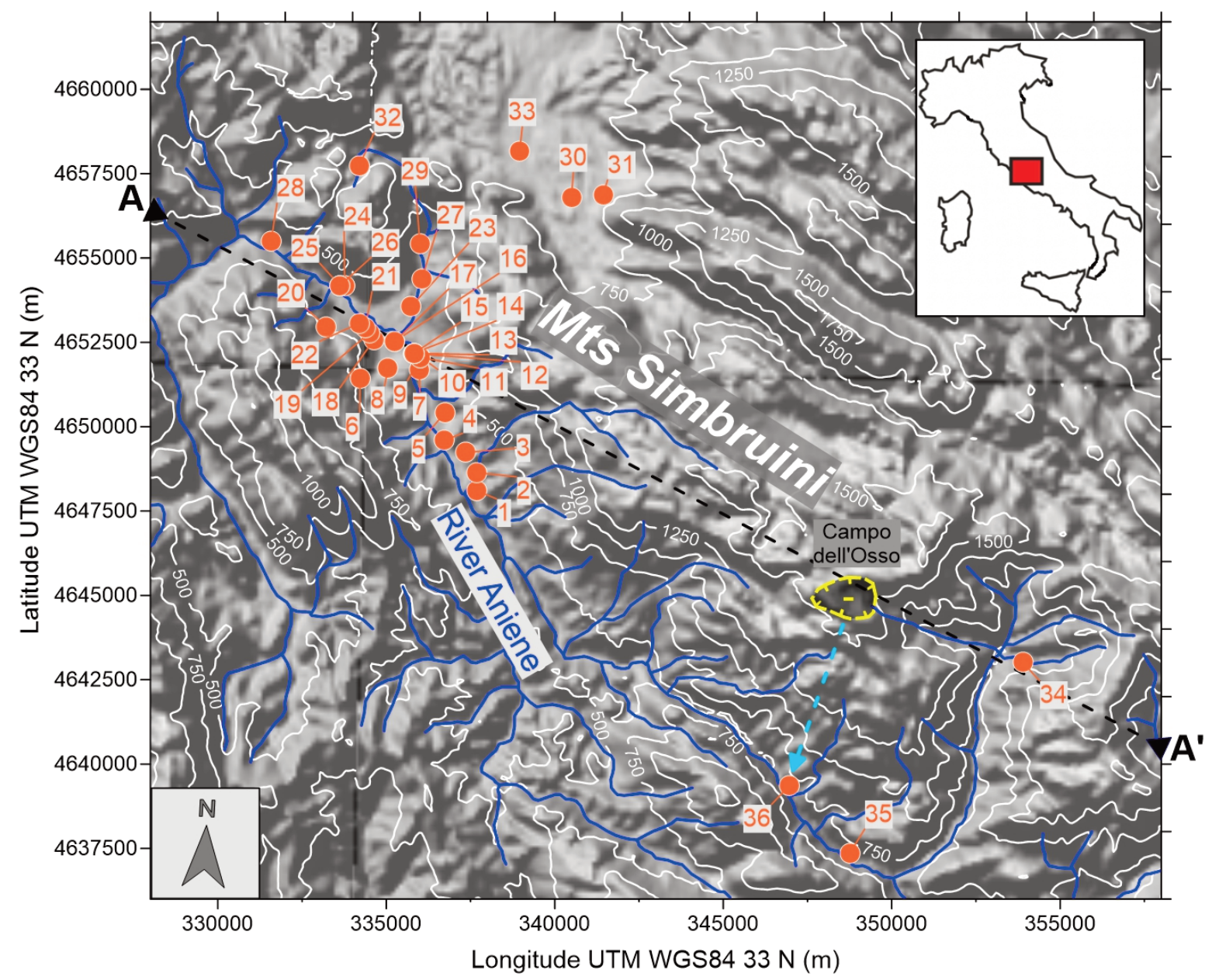

Figure 1. Location of the studied area (inset in the upper right) and shaded relief map reporting position of sampling points (orange circles), elevations (white lines, contour interval $250 \mathrm{~m}$ ) and the hydrographic network of the River Aniene (blue lines). Trace (A-A', dashed black line) of the hydrogeologic profile of Figure 3 and the endoreic karst plateau of Campo dell'Osso (in yellow) are also shown. The cyan dashed line indicates the fast karst hydrogeologic circuit connecting the Campo dell’Osso plateau with the resurgence of the "Inferniglio" (spring no. 36).

Some of the groundwaters contain free $\mathrm{CO}_{2}$ bubbles [Vinci, 1998] and to investigate the $\mathrm{CO}_{2}$ abundance and origin, we calculated the $\mathrm{PCO}_{2}$ in 36 samples and carried out $\delta^{13} \mathrm{C}$ isotopic analyses on the six 2019 groundwater samples.

Although all groundwaters are from a calcareous aquifer, minor but significant difference exist in their geochemical characteristics, which are mainly governed by water-rock interaction, and $\mathrm{CO}_{2}$-driven weathering.

In this paper we describe the geochemistry of the Simbruini karst aquifer and discuss the isotopic evidence that suggest the presence of local inputs of deep originated $\mathrm{CO}_{2}$. 


\section{Geological and hydrogeological outlines}

The study area is located in Central Italy, in the western part of Latium-Abruzzi Apennines, whose geodynamic evolution involves sedimentary complexes belonging to two contiguous paleogeographic domains. These are represented by the carbonatic platform series of Latium-Abruzzi (Upper Trias-Upper Cretaceous) and the Miocene Sabina transitional series [Fabbi, 2016].

In particular, the study area is located on the Simbruini-Ernici ridge belonging to the Latium-Abruzzi carbonate platform (Figures 1 and 2). This ridge is a big NE dipping monocline, overrun on the Upper Miocene Latium-Abruzzi siliciclastic deposits [Fabbri, 2016]. The Simbruini-Ernici ridge consists of three partially overlapped tectonic units. The most internal one consists mainly of $\sim 40^{\circ} \mathrm{NE}$ dipping Cretaceous calcareous sequences, overrun above the intermediate tectonic unit which is made of a monocline of dolomitic rocks (Dogger-Malm), with $45^{\circ} \mathrm{NNE}$ dipping. The external tectonic unit also consists mostly of a monocline of NNE dipping Cretaceous calcareous strata, which generate reverse faults at its front [Vinci, 1998].

The area is characterized by the presence of eight hydrogeological complexes (Figure 2) distinguished on the basis of the Aquifer Potential Evaluation (APE), i.e. their average permeability and water infiltration efficiency [Capelli et al., 2012]. The alluvial deposits complex is the most recent (Holocene), it has a low to medium-high APE and a thickness of a few meters to more than one hundred meters. The thickest deposits contain multilayer aquifers of regional importance. The detrital deposits complex (Pleistocene-Holocene) has a medium-high APE and a thickness up to a few tens of meters. It does not contain any significant aquifer apart from seasonal perched ones. The complex of marly arenaceous flysch (middle - upper Miocene) has a medium-low APE. It is some hundred meters thick without any water circulation of regional importance. The marly-limestone basin complex (Eocene-Miocene) has medium-low APE, with a maximum thickness of some hundred meters. This complex represents the hydraulic seal because of its high marl component. The marly-limestone platform complex (Upper Cretaceous-Miocene) has a medium-high APE, with thickness up to hundred meters. Limestones favour the recharge of the regional aquifers whereas the marly component sustains modest local aquifers. The marly-clayely flysch complex (Upper Cretaceous -Oligocene) has a very low APE, thickness up to $1000 \mathrm{~m}$ and does not host any aquifer. The most important hydrogeological complex is the platform limestone complex (Middle Cretaceous-Upper Lias) with a very high APE and a thickness ranging from a few hundred meters to $1500 \mathrm{~m}$. It hosts large aquifers feeding the main springs of Lazio Region. The basal dolomitic complex (Trias-Lower Lias) has a medium-low APE and thickness up to hundreds of meters. Its permeability is lower than that of the platform limestones and therefore it plays the role of base aquitard of the underground circulation.

In summary, the Mts. Simbruini form a large NW-SE hydrogeological complex, consisting of a $\sim 4000 \mathrm{~m}$ thick succession of calcareous rocks, surrounded at its base by low-permeability siliciclastic deposits, which insulate it hydraulically from the adjacent groundwater circulation systems [Vinci, 1998]. The carbonate rocks have a marked secondary permeability that favored the development of shallow and deep karst phenomena, allowing the formation of an important base aquifer, mainly flowing north-eastward and whose aquiclude is seated on the low permeability dolomites. Many springs spill out at the contact between the base dolomitic succession and the overlying calcareous rocks, presently almost totally used for the Marcio aqueduct of Rome city. A schematic hydrogeological cross section, whose trace (A-A') is reported in Figure 2 is illustrated in Figure 3.

\section{Materials and Methods}

Data of the present work are related to a previous unpublished study carried out in the second half of 1990s', integrated by new samples collected in May 2019. The first includes 30 samples, 23 of which from springs and 7 from wells [Vinci, 1998]. The second campaign was carried out in May 2019, far from the last heavy rains for avoiding the collection of samples perturbed by shallow, fast groundwater circulation, and includes 6 spring samples. Location of sampling sites is shown in Figure 1. Electric conductivity, pH and Eh were measured in the field using electrochemical sensors. Water samples of the 1996 campaign were first filtered using $0.45 \mu \mathrm{m}$ Millipore MF filter and then collected in 2L LD-PE (low-density polyethylene) bottles, acidifying with $\mathrm{HCl}$ to ca. pH 2 the aliquot destined to cation determination, which was carried out by atomic absorption spectroscopy.

$\mathrm{SO}_{4}{ }^{2-}$ and $\mathrm{NO}_{3}{ }^{-}$were determined by spectroscopy (Perkin Elmer MKIII), whereas chlorine content was determined by tritration. The May 2019 water samples were analysed at the lab facilities of Istituto Nazionale di Geofisica e 


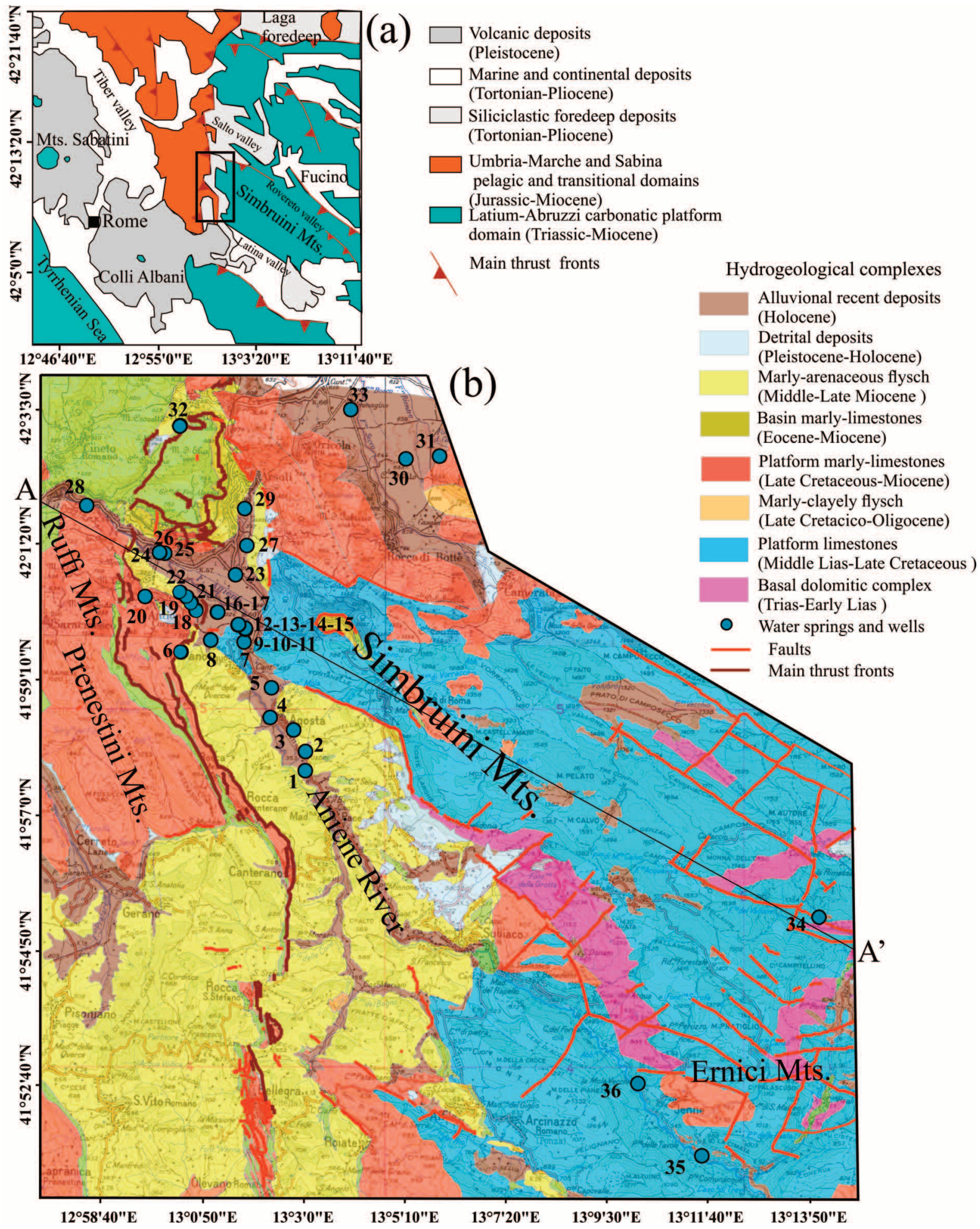

Figure 2. (a) Geology of Central Italy (modified after Carminati et al. [2014]). Black rectangle indicates the study area; (b) Schematic hydrogeological map of the Simbruini Mts. (modified after Capelli et al. [2012]). A-A' is the trace line of the cross-section of Figure 3. Base map Latium Regional Technical Cartography (CTR), scale 1:100.000 geographical coordinates in WGS 84 . 
Vulcanologia (INGV), Sezione di Palermo. Samples used for the determination of dissolved major and trace elements, were first filtered using $0.45 \mu \mathrm{m}$ Millipore MF filter and then collected in LD-PE bottles for major element analyses, acidifying with $\mathrm{HNO}_{3}{ }^{-}$to ca. $\mathrm{pH} 2$ the aliquot destined to cation determination. Untreated aliquots were collected for isotopic and alkalinity determinations, made via tritration with $\mathrm{HCl}(0.1 \mathrm{~N})$. Major ions were determined by ionic chromatography, using Dionex columns AS14 and CS12 for anions and cations respectively.

We used the PHREEQC software [Parkhurst and Appelo, 2020] for calculating saturation indexes of calcite and partial pressure $\mathrm{CO}_{2}\left(\mathrm{PCO}_{2}\right)$, adopting the LLNL database. Starting from anaylitcal data, we calculated the $\mathrm{PCO}_{2}$ in the sampled waters from $\mathrm{pH}$ and alkalinity using the constants $\mathrm{K}_{\mathrm{H}}$ and $\mathrm{K}_{1}$ once the temperature is known, following the procedure reported by Cangemi et al. [2020]. The calculated $\mathrm{PCO}_{2}$ values were plotted in a contour map using Golden Software Surfer (release 13), with the kriging interpolation algorithm.

Samples for analyses of dissolved gases and $\delta^{13} \mathrm{C}$ of Total Dissolved Inorganic Carbon (TDIC) were collected in glass bottles, hermetically capped with a crimper.

The determination of $\delta^{2} \mathrm{H}$ [Kracht, et al., 2016] and $\delta^{18} \mathrm{O}$ [Andreas and Hairigh, 2008] of water was performed by using a Thermo Delta Plus XP IRMS, coupled with an online pyrolysis system (TC/EA Thermal Conversion Elemental Analyzer) for ${ }^{2} \mathrm{H} /{ }^{1} \mathrm{H}$ ratio, and by $\mathrm{CO}_{2}$-water equilibration technique using a Thermo Delta V Plus instrument, equipped with a Gas Bench II, for ${ }^{18} \mathrm{O} /{ }^{16} \mathrm{O}$ ratio. The results were reported in $\mathrm{d} \%$ o versus the V-SMOW standard, with a precision better than $\pm 1 \%$ o for $\mathrm{d}^{2} \mathrm{H}$ and $\pm 0.1 \%$ for $\delta^{18} \mathrm{O}$. The isotopic composition of the Total Dissolved Inorganic Carbon $\left({ }^{13} \mathrm{C}_{\text {TDIC }}\right.$ ) was determined with the method proposed by Capasso et al. [2005], using a Thermo Delta V Plus IRMS coupled with an on-line gas preparation system Gas Bench II. The results were reported in $\delta \%$ versus the VPDB standard, with a precision better than $\pm 0.1 \%$. The correspondent values of $\delta^{13} \mathrm{C}$ of $\mathrm{CO}_{2}$ in equilibrium with TDIC, used in graphical representations, were calculated using the formula proposed by Zhang et al. [1995].

The chemical composition of the dissolved gasses $\left(\mathrm{CH}_{4}\right.$ and $\left.\mathrm{CO}_{2}\right)$ was determined according to the procedure by Capasso and Inguaggiato [1998]; this method is based on the equilibrium between the liquid and the gas phases in the headspace of the bottles. We used an Agilent (Santa Clara, CA, USA) 78909 GC instrument, with Ar as gas carrier and TCD-FID as detectors; analytical accuracy was better than $5 \%$.

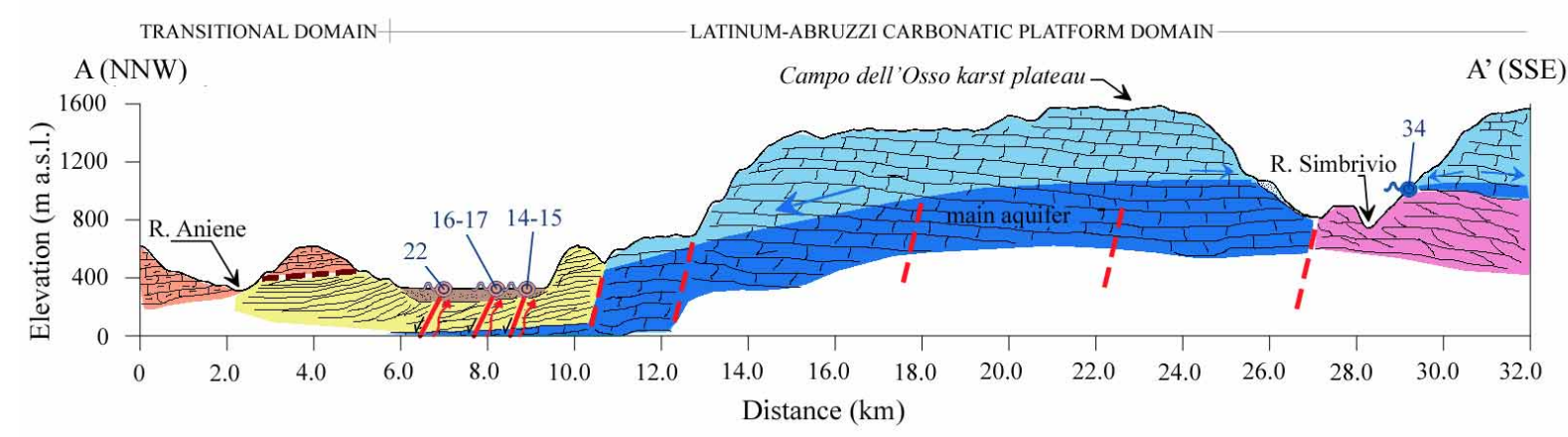

Hydrogeological complexes

\begin{tabular}{lcccc}
$\square$ Detrital deposits & $\square$ Platform marly-limestones \\
$\square$ Alluvional recent deposits & $\square$ Marly-arenaceous flysch \\
\hline Faults certain/supposed & Main thrust fronts & Groundwater flow direction & Water springs and wells Hydrothermal gas uprise
\end{tabular}

Figure 3. Schematic hydrogeological profile of the studied area (trace shown in Figure 1 and 2). 


\section{Marianna Cangemi et al.}

\section{Results and Discussion}

\subsection{Physical, Chemical and Isotopic Characteristics of Groundwater}

Field data are reported in Table 1. Groundwater samples are characterized by an average electrical conductivity (E.C.) of $\sim 925 \mu \mathrm{S} \mathrm{cm}^{-1}$, with a minimum of $340 \mu \mathrm{S} \mathrm{cm}^{-1}$ (INF spring no. 36) and a maximum of $2380 \mu \mathrm{Scm}^{-1}$ recorded at no. 13 spring. The average value of $\mathrm{pH}$ is $\sim 6.95$, with a minimum of 6.04 and a maximum of 8.30. Chemical data are reported in Table 2; Table 3 shows the additional data (isotopic compositions and Eh) related to the 2019 field campaign. The most abundant cation is $\mathrm{Ca}^{2+}$ (mean concentration $\left.196 \mathrm{mg} \mathrm{L}^{-1}\right)$, followed by $\mathrm{Mg}^{2+}\left(29.9 \mathrm{mg} \mathrm{L}^{-1}\right)$ and to a minor extent, by $\mathrm{Na}^{+}$and $\mathrm{K}^{+}$(7.68 and $2.05 \mathrm{mg} \mathrm{L}^{-1}$, respectively).

\begin{tabular}{|c|c|c|c|c|c|c|c|c|}
\hline Id. & Lon. & Lat. & Elevation (m) & Date & $\mathrm{T}\left({ }^{\circ} \mathrm{C}\right)$ & pH & $\begin{array}{c}\text { E.C. } \\
\left(\mu \mathrm{S} \mathrm{cm}^{-1}\right)\end{array}$ & Source* \\
\hline $1 \mathrm{w}$ & 13.0412 & 41.9682 & 335 & May 1996 & 11.8 & 6.83 & 850 & 2 \\
\hline 2 & 13.0410 & 41.9731 & 360 & May 1996 & 13.5 & 7.72 & 350 & 2 \\
\hline 3 & 13.0369 & 41.9784 & 350 & May 1996 & 12.3 & 7.14 & 575 & 2 \\
\hline 4 & 13.0289 & 41.9814 & 328 & May 1996 & 11.8 & 7.14 & 560 & 2 \\
\hline 5 & 13.0291 & 41.9888 & 330 & May 1996 & 10.1 & 7.08 & 505 & 2 \\
\hline 6 & 12.9984 & 41.9974 & 550 & May 1996 & 12.2 & 8.3 & 385 & 2 \\
\hline 7 & 13.0195 & 42.0002 & 328 & May 1996 & 12.3 & 6.98 & 685 & 2 \\
\hline 8 & 13.0082 & 42.0004 & 330 & May 1996 & 11.5 & 7.15 & 600 & 2 \\
\hline 9 & 13.0199 & 42.0034 & 328 & May 1996 & 14.5 & 6.29 & 1587 & 2 \\
\hline 10 & 13.0198 & 42.0034 & 328 & May 1996 & 13.6 & 6.4 & 1329 & 2 \\
\hline 11 & 13.0198 & 42.0036 & 328 & May 1996 & 14.1 & 6.42 & 1372 & 2 \\
\hline 12 & 13.0174 & 42.0044 & 328 & May 1996 & 13.2 & 6.26 & 1935 & 2 \\
\hline 13 & 13.0176 & 42.0045 & 328 & May 1996 & 17.2 & 6.11 & 2380 & 2 \\
\hline 14 & 13.0175 & 42.0045 & 328 & May 1996 & 12.4 & 6.53 & 985 & 2 \\
\hline 15 & 13.0175 & 42.0045 & 326 & May 2019 & 17.1 & 6.04 & 2031 & 1 \\
\hline 16 & 13.0103 & 42.0075 & 324 & May 1996 & 15.5 & 6.3 & 2110 & 2 \\
\hline 17 & 13.0104 & 42.0075 & 323 & May 2019 & 16.6 & 6.35 & 1990 & 1 \\
\hline 18 & 13.0030 & 42.0079 & 325 & May 1996 & 12.2 & 6.74 & 846 & 2 \\
\hline 19 & 13.0014 & 42.0097 & 327 & May 1996 & 12.9 & 6.63 & 960 & 2 \\
\hline 20 & 12.9859 & 42.0110 & 500 & May 1996 & 12 & 7.75 & 408 & 2 \\
\hline 21 & 12.9999 & 42.0111 & 330 & May 1996 & 13.2 & 6.5 & 1080 & 2 \\
\hline 22 & 12.9977 & 42.0122 & 327 & May 1996 & 13 & 6.54 & 1072 & 2 \\
\hline 23 & 13.0161 & 42.0170 & 329 & May 2019 & 11.5 & 7.51 & 577 & 1 \\
\hline $24 w$ & 12.9921 & 42.0220 & 345 & May 1996 & 12.6 & 7.01 & 732 & 2 \\
\hline 25 & 12.9904 & 42.0221 & 328 & May 1996 & 11.5 & 6.86 & 710 & 2 \\
\hline 26 & 12.9904 & 42.0221 & 328 & May 1996 & 11 & 6.94 & 641 & 2 \\
\hline $27 w$ & 13.0197 & 42.0244 & 347 & May 1996 & 12.2 & 7.06 & 615 & 2 \\
\hline $28 w$ & 12.9654 & 42.0335 & 320 & May 1996 & 12.9 & 6.3 & 1715 & 2 \\
\hline 29 & 13.0187 & 42.0337 & 355 & May 1996 & 11.4 & 7.07 & 622 & 2 \\
\hline $30 w$ & 13.0726 & 42.0471 & 686 & May 1996 & 13.1 & 7.57 & 450 & 2 \\
\hline $31 w$ & 13.0840 & 42.0480 & 665 & May 1996 & 13.3 & 7.45 & 438 & 2 \\
\hline 32 & 12.9963 & 42.0541 & 700 & May 1996 & 10.6 & 7.28 & 510 & 2 \\
\hline $33 w$ & 13.0537 & 42.0591 & 620 & May 1996 & 12.8 & 7.33 & 560 & 2 \\
\hline 34 & 13.2378 & 41.9256 & 885 & May 2019 & 9.7 & 7.47 & 404 & 1 \\
\hline 35 & 13.1774 & 41.8737 & 540 & May 2019 & 13.1 & 7.65 & 408 & 1 \\
\hline 36 & 13.1554 & 41.8915 & 526 & May 2019 & 9.9 & 7.47 & 340 & 1 \\
\hline
\end{tabular}

Table 1. Location and field parameters of water samples.

*1: this paper; 2: after [Stevanovic, 2015]. "w” indicates that the sample is from a well; all other samples are from springs. 
Geochemistry of Mts. Simbruini aquifers

\begin{tabular}{|c|c|c|c|c|c|c|c|c|c|c|}
\hline Id. & $\mathrm{Na}^{+}$ & $\mathrm{K}^{+}$ & $\mathrm{Mg}^{2+}$ & $\mathrm{Ca}^{2+}$ & $\mathrm{Cl}^{-}$ & $\mathrm{NO}_{3}^{-}$ & $\mathrm{SO}_{4}^{2-}$ & $\mathrm{HCO}_{3}^{-}$ & $\mathrm{PCO}_{2}$ & SI calcite \\
\hline $1 \mathrm{w}$ & 3.22 & 0.39 & 18.7 & 166 & 16 & 15.5 & 69.2 & 494 & 0.07 & 0.084 \\
\hline 2 & 2.99 & 0.78 & 9.12 & 80.4 & 5.32 & 0.06 & 0.48 & 275 & 0.005 & 0.52 \\
\hline 3 & 4.83 & 1.56 & 15.6 & 115 & 14.2 & 0.62 & 8.17 & 397 & 0.028 & 0.199 \\
\hline 4 & 3.22 & 0.78 & 21.5 & 111 & 7.09 & 1.86 & 0.961 & 429 & 0.03 & 0.207 \\
\hline 5 & 2.3 & 0.78 & 22.2 & 109 & 5.32 & 0.62 & 1.92 & 414 & 0.033 & 0.101 \\
\hline 6 & 2.99 & 0.78 & 10.3 & 80.4 & 5.32 & 0.31 & 1.92 & 281 & 0.001 & 1.066 \\
\hline 7 & 2.99 & 0.78 & 24.7 & 130 & 10.6 & 0.62 & 1.44 & 489 & 0.05 & 0.163 \\
\hline 8 & 4.37 & 0.78 & 20.7 & 120 & 0.89 & 0.62 & 12.5 & 445 & 0.03 & 0.254 \\
\hline 9 & 36.6 & 8.99 & 56.5 & 360 & 5.32 & 0.62 & 212 & 1222 & 0.579 & 0.174 \\
\hline 10 & 3.45 & 1.56 & 28.7 & 300 & 5.32 & 0.62 & 23.1 & 1017 & 0.379 & 0.18 \\
\hline 11 & 3.45 & 1.56 & 36.5 & 288 & 8.86 & 0 & 17.8 & 1031 & 0.369 & 0.194 \\
\hline 12 & 4.6 & 3.13 & 31.4 & 485 & 8.86 & 0.62 & 21.1 & 1623 & 0.799 & 0.369 \\
\hline 13 & 38.9 & 8.6 & 69.6 & 543 & 5.32 & 0.62 & 186 & 1891 & 1.35 & 0.335 \\
\hline 14 & 3.45 & 1.17 & 26.6 & 196 & 5.32 & 0.62 & 10.6 & 732 & 0.205 & 0.019 \\
\hline 15 & 4.67 & & 124 & 431 & 11.9 & & 20.9 & 1867 & 1.57 & 0.182 \\
\hline 16 & 56.3 & 7.43 & 82.3 & 490 & 8.86 & 0.62 & 265 & 1709 & 0.776 & 0.418 \\
\hline 17 & 4.51 & & 125 & 409 & 11 & & 18.3 & 1847 & 0.759 & 0.462 \\
\hline 18 & 3.91 & 0.39 & 25 & 162 & 3.55 & 1.24 & 3.36 & 604 & 0.105 & 0.085 \\
\hline 19 & 4.6 & 1.56 & 28 & 191 & 7.09 & 1.86 & 3.84 & 709 & 0.159 & 0.105 \\
\hline 20 & 3.68 & 0.78 & 2.43 & 93 & 8.86 & 0.62 & 3.36 & 275 & 0.005 & 0.587 \\
\hline 21 & 4.6 & 1.56 & 32.5 & 223 & 5.32 & 0.62 & 21.1 & 811 & 0.243 & 0.081 \\
\hline 22 & 4.6 & 1.56 & 30 & 207 & 3.55 & 0.62 & 4.32 & 799 & 0.219 & 0.09 \\
\hline 23 & 7.54 & & 20.2 & 107 & 10.8 & 3.64 & 9.63 & 404 & 0.012 & 0.528 \\
\hline $24 w$ & 5.75 & 2.35 & 25.4 & 136 & 8.86 & 2.48 & 12.5 & 549 & 0.052 & 0.254 \\
\hline 25 & 8.28 & 1.17 & 30 & 117 & 7.09 & 7.44 & 8.65 & 512 & 0.068 & 0.001 \\
\hline 26 & 3.22 & 0.78 & 21.5 & 134 & 7.09 & 0.62 & 8.65 & 512 & 0.056 & 0.134 \\
\hline $27 w$ & 6.9 & 1.95 & 13.9 & 147 & 12.4 & 0.62 & 8.65 & 525 & 0.044 & 0.319 \\
\hline $28 w$ & 2.99 & 0.78 & 21.6 & 411 & 8.86 & 0.62 & 12.5 & 1354 & 0.617 & 0.288 \\
\hline 29 & 6.44 & 1.95 & 10.3 & 126 & 8.86 & 5.58 & 10.6 & 429 & 0.035 & 0.183 \\
\hline $30 w$ & 3.91 & 2.74 & 18.7 & 61.9 & 8.86 & 0.62 & 1.92 & 287 & 0.008 & 0.27 \\
\hline $31 \mathrm{w}$ & 5.98 & 3.52 & 13.1 & 68.1 & 12.4 & 0.62 & 7.21 & 280 & 0.01 & 0.185 \\
\hline 32 & 7.82 & 0.78 & 8.87 & 110 & 16 & 0 & 19.7 & 334 & 0.017 & 0.23 \\
\hline $33 w$ & 4.37 & 0.39 & 25.5 & 118 & 12.4 & 12.4 & 8.65 & 440 & 0.02 & 0.435 \\
\hline 34 & 2.41 & & 15.4 & 76 & 4.04 & & 2.69 & 304 & 0.01 & 0.227 \\
\hline 35 & 3.45 & & 3.74 & 92.6 & 5.48 & 0.98 & 3.05 & 282 & 0.006 & 0.514 \\
\hline 36 & 3.24 & & 6.83 & 65.1 & 6.29 & 1.58 & 2.42 & 229 & 0.008 & 0.067 \\
\hline
\end{tabular}

Table 2. Element concentration (in $\mathrm{mg} \mathrm{L}^{-1}$ ), $\mathrm{PCO}_{2}$ (atm) and saturation index (SI) of calcite of ground waters.

*1: this paper; 2: after [Vinci, 1998]. "w" indicates that the sample is from a well; all other samples are from springs.

In decreasing order of abundance, anions are represented by $\mathrm{HCO}_{3}^{-}$(mean value $716 \mathrm{mg} \mathrm{L}^{-1}$ ), $\mathrm{SO}_{4}{ }^{2-}$ (mean value $28.5 \mathrm{mg} \mathrm{L}^{-1}$ ), $\mathrm{Cl}^{-}$(mean value $8.14 \mathrm{mg} \mathrm{L}^{-1}$ ) and $\mathrm{NO}_{3}^{-}$(mean value $2 \mathrm{mg} \mathrm{L}^{-1}$ ). The relative abundances of the main dissolved ions classify the studied groundwater as bicarbonate alkaline-earth type, as shown in the Langelier-Ludwig diagram (Figure 4); minor contributions of $\mathrm{Na}^{+}$and $\mathrm{K}^{+}$are also evidenced. The anion ternary diagram (Figure 5a) further confirms that the quasi totality of samples falls close to the $\mathrm{HCO}_{3}$ - corner, with a trend moving toward the $\mathrm{SO}_{4}$ vertex, confirming that the aquifer is mainly constituted by carbonate rocks. The cation ternary diagram (Figure $5 b$ ) indicates that, apart $\mathrm{Ca}^{2+}$ that represents the main cation, a variable amount of $\mathrm{Mg}^{2+}$ occurs in the groundwater.

Figure 6a shows the total alkalinity against the sum of cations ( $\sum$ cat). All samples fall close to the 1:1 line, indicating that weathering driven by $\mathrm{CO}_{2}$ is the main process controlling the chemical composition of the water. Moreover, Figure $6 \mathrm{~b}$ shows a direct relationship between $\mathrm{Ca}^{2+}+\mathrm{Mg}^{2+}$ and the total alkalinity. High $\mathrm{Ca}^{2+} \mathrm{and}^{\mathrm{Mg}^{2+}}$ 


\section{Marianna Cangemi et al.}

levels in groundwater are mainly recorded when the aquifers are made of carbonate rocks, pointing out that waterrock interaction is the main source of these dissolved ions. Furthermore, calculated $\mathrm{PCO}_{2} \mathrm{vs}$. $\mathrm{Ca}^{2+}+\mathrm{Mg}^{2+}$ diagram (Figure 6c) indicates a direct relationship between these two parameters.

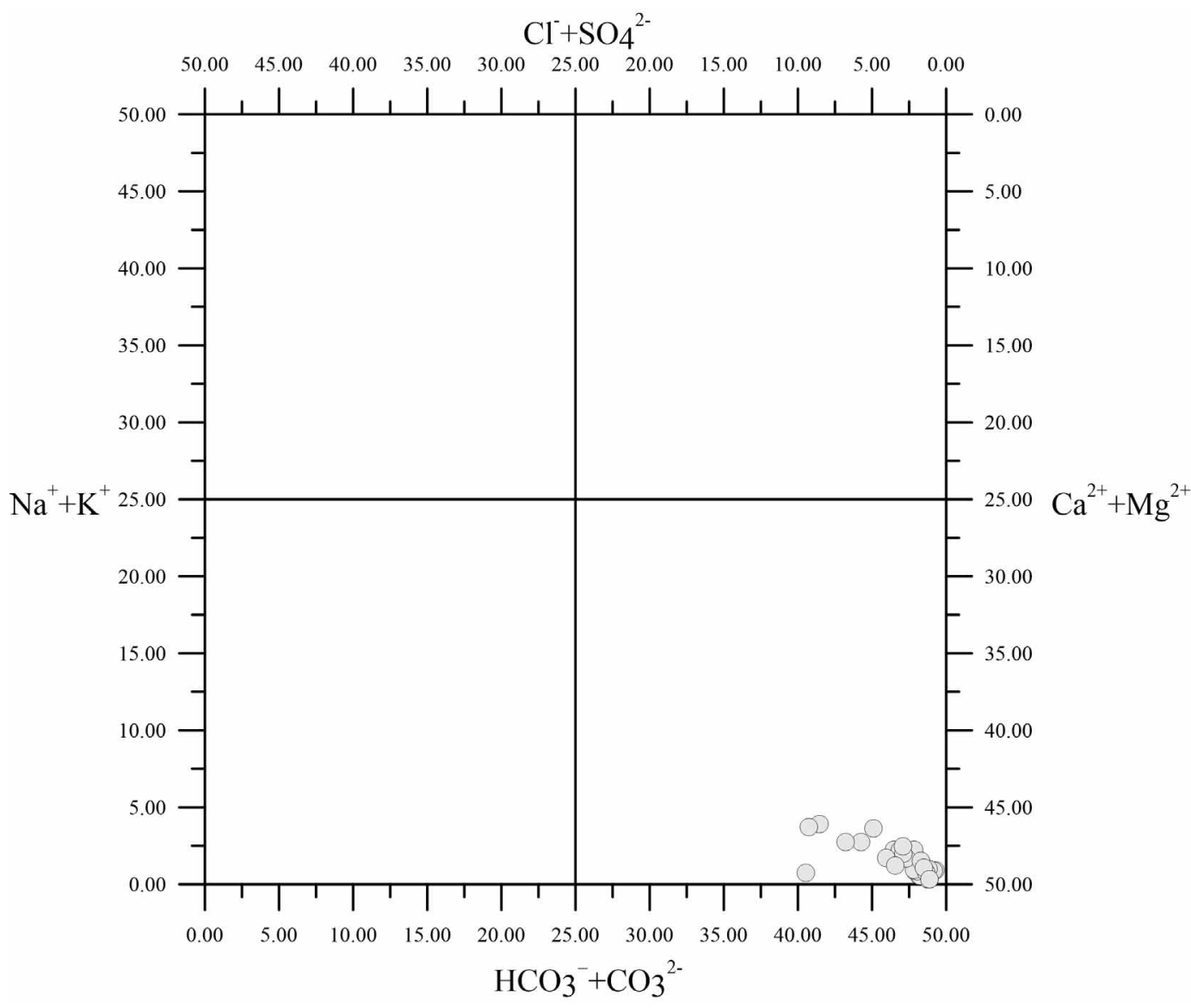

Figure 4. Plot of Simbruini groundwaters in the Langelier-Ludwig diagram.

Saturation indexes (Figure 6d) indicate that groundwaters are at equilibrium or oversaturated with respect to calcite. Saturation indexes are not related to calculated $\mathrm{PCO}_{2}$ when this parameter is low. Conversely, SI are directly related to $\mathrm{PCO}_{2}$ in samples exhibiting higher carbon dioxide contents.

We used probability plots for identifying different populations of data [Sinclair, 1974]. Generally, data belonging to a single population are distributed along a straight line, so the presence of multiple straight lines with different slopes indicates the occurrence of various populations with a different origin. Probability plots of $\mathrm{HCO}_{3}{ }^{-}$, Scations and $\mathrm{Ca}^{2+}$ $+\mathrm{Mg}^{2+}$ exhibit a similar distribution, with tree inflection points reflecting four populations of data (Figure 7). The first two populations include ca. $70 \%$ of the samples, ca. $28 \%$ of the samples are in population III and the remaining $2 \%$ is contained in population IV, composed of samples with the highest $\mathrm{PCO}_{2}$ values, whose maxima are found in samples 13 and 15 .

The concentration of dissolved $\mathrm{CH}_{4}$ and $\mathrm{CO}_{2}$ are reported in Table 3 (2019 samples). Sites 15 and 17 exhibit the highest concentrations for both species, whereas in the other samples their concentrations are 2-3 order of magnitude lower. $\delta^{2} \mathrm{H}$ and $\delta^{18} \mathrm{O}$ values range from -56.6 to $-45.2 \%$ and -9.4 to $-7.9 \%$ (vs V-SMOW) respectively (Table 3). These values are reported in the $\delta^{18} \mathrm{O}$ vs $\delta^{2} \mathrm{H}$ diagram of Figure 8, also showing reference data [Madonia, et al., 2020] for other karst aquifers of Central Italy and the lines representative of groundwater [Celico, et al., 1984] and rainwater [Longinelli and Selmo, 2003] for the study area, and the Global Meteoric Water Line (GMWL) [Craig, 1961]. The points fall in the area of groundwater by [2015], being shifted upward with respect to the rainwater line of [Longinelli and Selmo, 2003]. 


\section{Geochemistry of Mts. Simbruini aquifers}
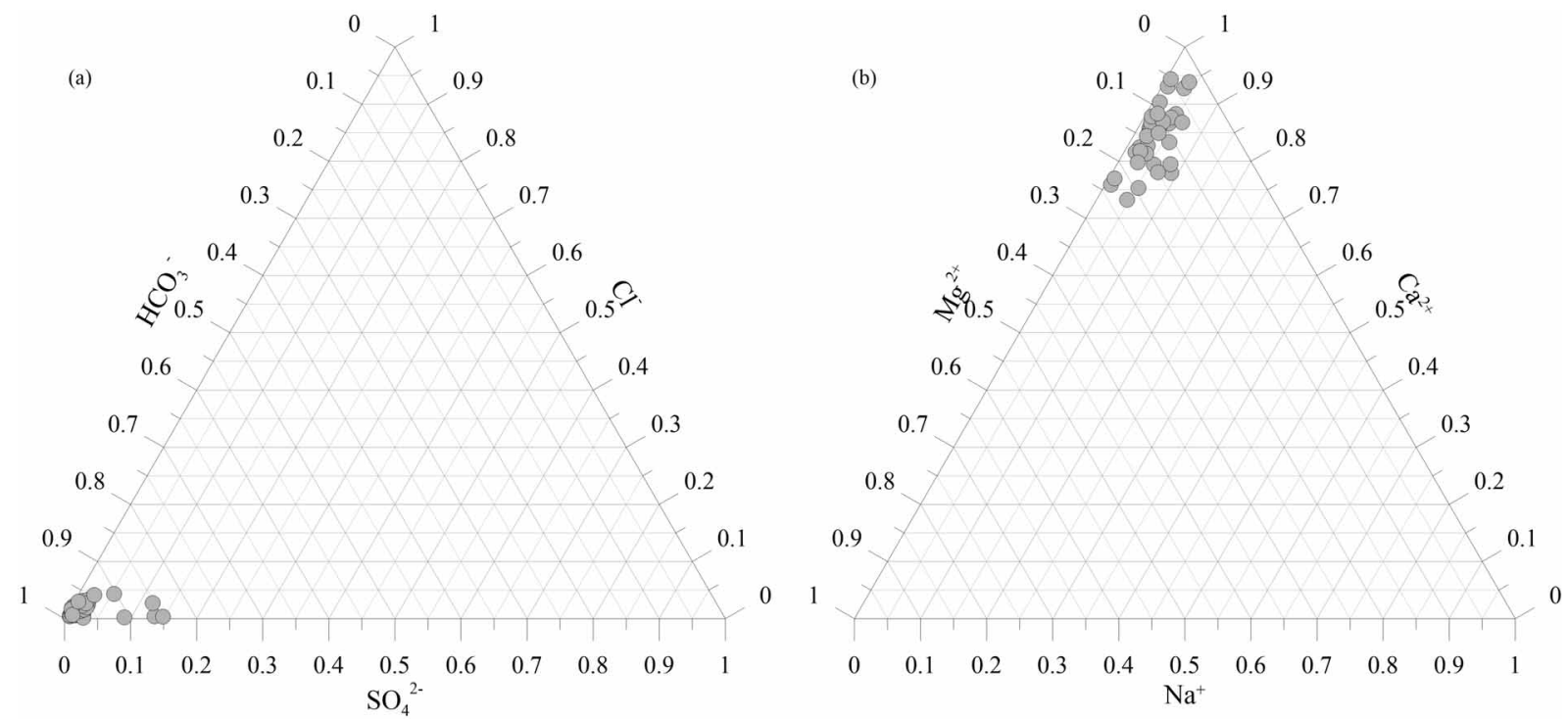

Figure 5. Plot of Simbruini groundwaters in the ternary $\mathrm{HCO}_{3}{ }^{-}-\mathrm{SO}_{4}{ }^{2-}-\mathrm{Cl}^{-}$a) and $\mathrm{Ca}^{2+}-\mathrm{Na}^{+}-\mathrm{Mg}^{2+}$ b) diagrams.
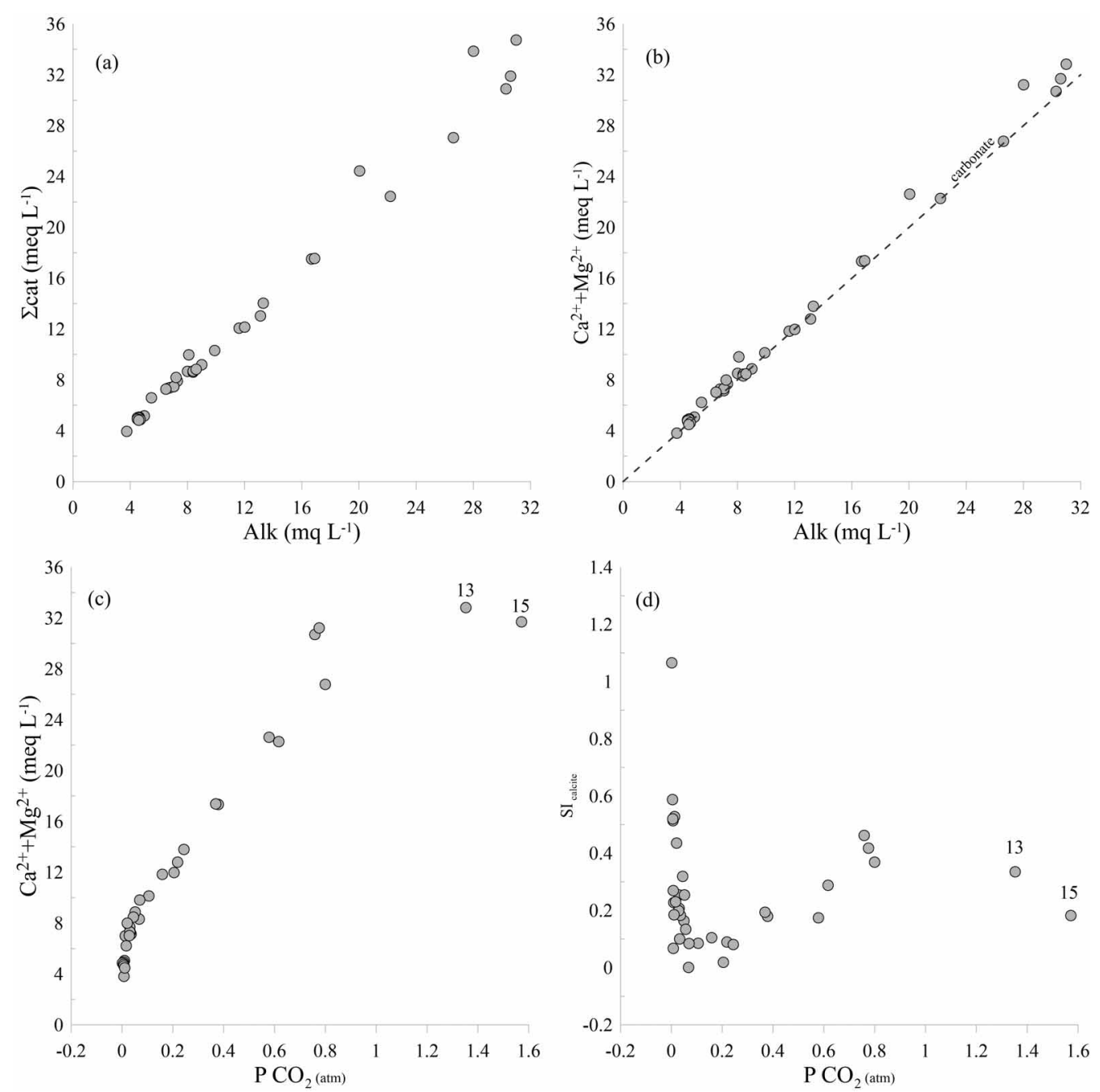

Figure 6. Binary chemical plots of Simbruini groundwaters. a) Alkalinity vs. $\Sigma$ cations; b) Alkalinity vs. $\mathrm{Ca}^{2+}+\mathrm{Mg}^{2+}$; c) $\mathrm{PCO}_{2}$ vs. $\mathrm{Ca}^{2+}+\mathrm{Mg}^{2+} ;$ d) $\mathrm{PCO}_{2}$ vs. SI. 


\section{Marianna Cangemi et al.}
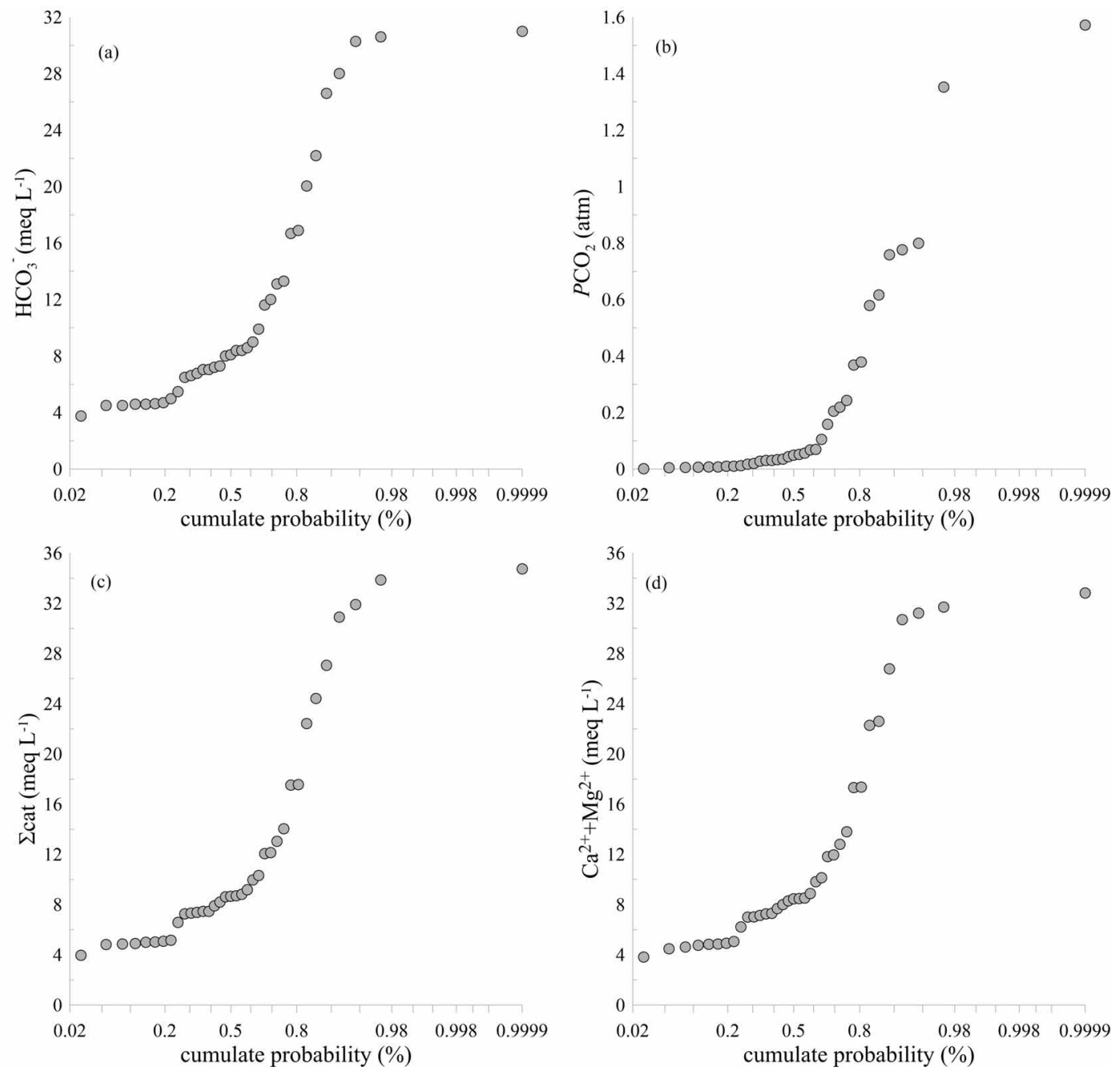

Figure 7. Probability plots of $\mathrm{HCO}_{3}{ }^{-} \mathrm{a}$ ), $\mathrm{PCO}_{2} \mathrm{~b}$ ), sum of cations ( $\Sigma$ cat) c), and $\mathrm{Ca}^{2+}+\mathrm{Mg}^{2+} \mathrm{d}$ ), for the Simbruini groundwaters.

\begin{tabular}{|c|c|c|c|c|c|c|c|}
\hline Id. & $\delta^{18} 0$ & $\delta^{2} \mathrm{H}_{\mathrm{H} 2 \mathrm{O}}$ & $\delta^{13} C_{\text {TDIC }}$ & $\delta^{13} \mathrm{CCO}_{2}$ & $\mathrm{CH}_{4}$ & $\mathrm{CO}_{2}$ & Eh \\
\hline 15 & -9.4 & -57 & 5.8 & 1.7 & 3.95E-02 & 775 & 37 \\
\hline 17 & -9.2 & -56 & 7.4 & 2.6 & $7.41 \mathrm{E}-02$ & 575 & 20 \\
\hline 23 & -8.6 & -52 & -6.0 & -15. & & & -43.4 \\
\hline 34 & -8.3 & -48 & -13 & -22 & $7.98 \mathrm{E}-05$ & 7.6 & -41.4 \\
\hline 35 & -7.9 & -45 & -12 & -21 & $1.20 \mathrm{E}-04$ & 5.0 & -51 \\
\hline 36 & -9.2 & -52 & -12 & -21 & & 4.3 & -42 \\
\hline
\end{tabular}

Table 3. Oxygen, deuterium (\%o vs. V-SMOW) isotopic composition, carbon isotopic compositions of dissolved $\mathrm{CO}_{2}$ (\%o vs. $\mathrm{PDB}$ ), dissolved $\mathrm{CH}_{4}$ and $\mathrm{CO}_{2}$ contents (cc $\left.\mathrm{L}^{-1} \mathrm{STP}\right)$ and $\mathrm{Eh}(\mathrm{mV}$, measured in the field) of groundwater samples collected in 2019. 


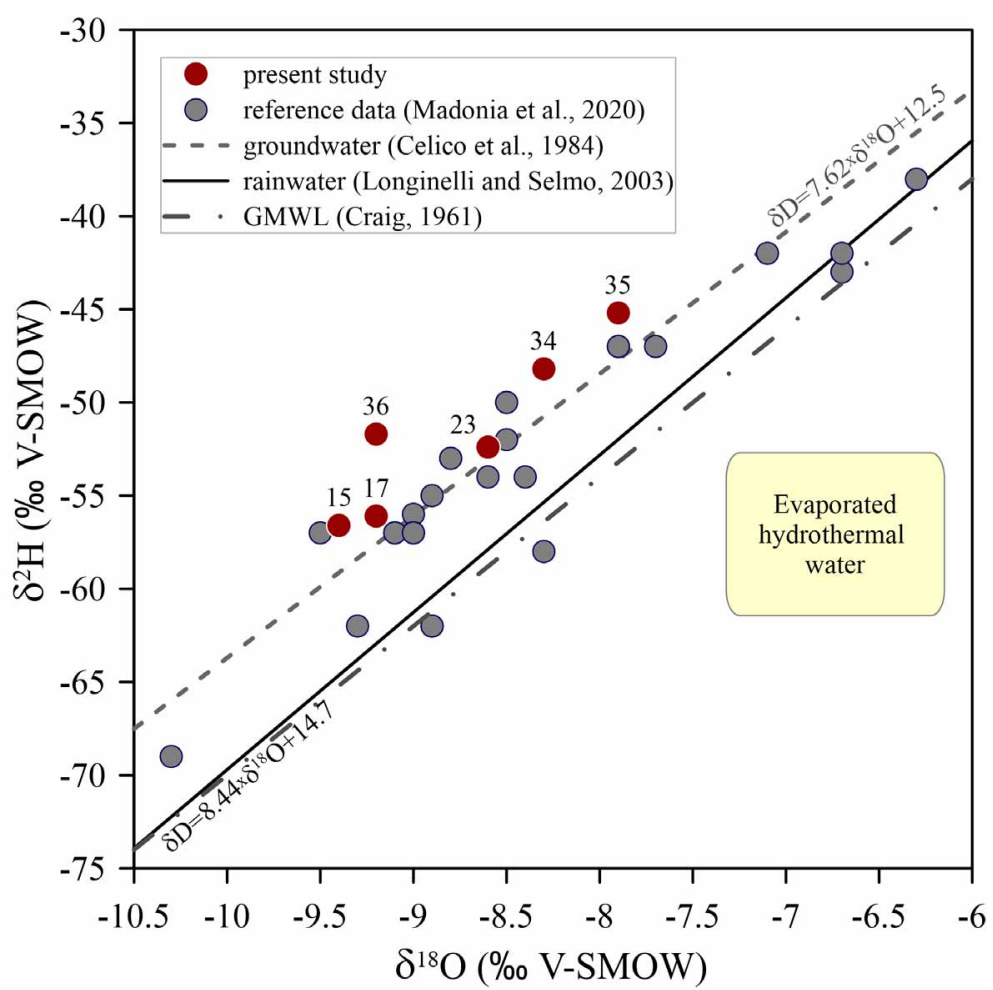

Figure 8. Plot of $\delta^{18} \mathrm{O}$ vs $\delta^{2} \mathrm{H}$ of samples collected in 2019. Reference data for other karst aquifer of Central Italy [Madonia, et al., 2020] are reported together with reference lines for groundwater [Celico, 1983] and for rainwater of Central Italy [Longinelli and Selmo, 2003], and the GMWL [Craig, 1961].

\subsection{Inferences on groundwater circulation from chemical and isotopic data}

The Langelier-Ludwig diagram (Figure 4) remarks that the samples fall in the bicarbonate alkaline-earth quadrant, as expected for karst water dominated by the dissolution of carbonate rocks, both limestones and dolostones, as remarked by the slight variability of $\mathrm{Mg}^{2+}$ concentrations (Figure 5b). In addition, a slight trend is observed toward a progressive enrichment in chlorine and sulphate. The ternary anion diagram (Figure 5a) indicates that this trend is driven by the delivery of sulphate, whose origin can be attributed to the interaction with sulfur gaseous species as $\mathrm{H}_{2} \mathrm{~S}$. We excluded a possible chemical interaction with evaporitic deposits since these, as evidenced by the AGIP well Trevi 1, drilled in this area for hydrocarbon exploration, found evaporites at a depth of $2168 \mathrm{~m}$ b.w.h., too high for hypothesizing an involvement in the groundwater circulation system of Mts. Simbruini. [Dondi et al., 1966].

The $\mathrm{SO}_{4}{ }^{2-}$-richest samples are from the sites 1, 9-13, 15-17 and 21, and two of them (15 and 17) have also high dissolved $\mathrm{CO}_{2}$ and $\mathrm{CH}_{4}$ concentrations and calculated $\mathrm{PCO}_{2}$. These sites are spatially clustered in the north-western corner of the studied area (Figure 1), suggesting the presence of tectonic discontinuities through which hydrothermal gases can migrate from depth interacting with the karst aquifers, as already suggested in previous studies [Percopo, 1998] and schematized in the hydrogeological profile of Figure 3.

This area is well defined in the $\mathrm{PCO}_{2}$ map (Figure 9), where an anomaly is depicted by $\mathrm{PCO}_{2}$ values exceeding 0.3 atm found in 8 sites. Another isolated, anomalous $\mathrm{PCO}_{2}$ value has been recorded more to NW at the site 28 (an old roman-type dismissed well [Vinci, 1998]). Inferences on the origin of this $\mathrm{CO}_{2}$ excess are given by the isotopic composition of total dissolved carbon (available only for 2019 samples). It is worth noting that the two samples with $\mathrm{PCO}_{2}>0.3$ atm have a distinctly positive $\delta^{13} \mathrm{C}$ (1.65 and $2.63 \%$, for samples 15 and 17, respectively), contrasting with the negative values (-15.49 to $-22.15 \%$ o) of the samples with low $\mathrm{PCO}_{2}$ (0.006 to $\left.0.012 \mathrm{~atm}\right)$, typical of its organic origin, as expected in karst areas [Chiodini, et al., 1999]. The carbon isotopic composition of samples 15 and 17 is similar to that of the $\mathrm{CO}_{2}$ discharged from the near Colli Albani quiescent volcano (Figure 1), which is considered of deep magmatic origin, being associated to a ${ }^{3} \mathrm{He} /{ }^{4} \mathrm{He}$ value of magmatic imprinting [Carapezza, et al., 2020]. 


\section{Marianna Cangemi et al.}

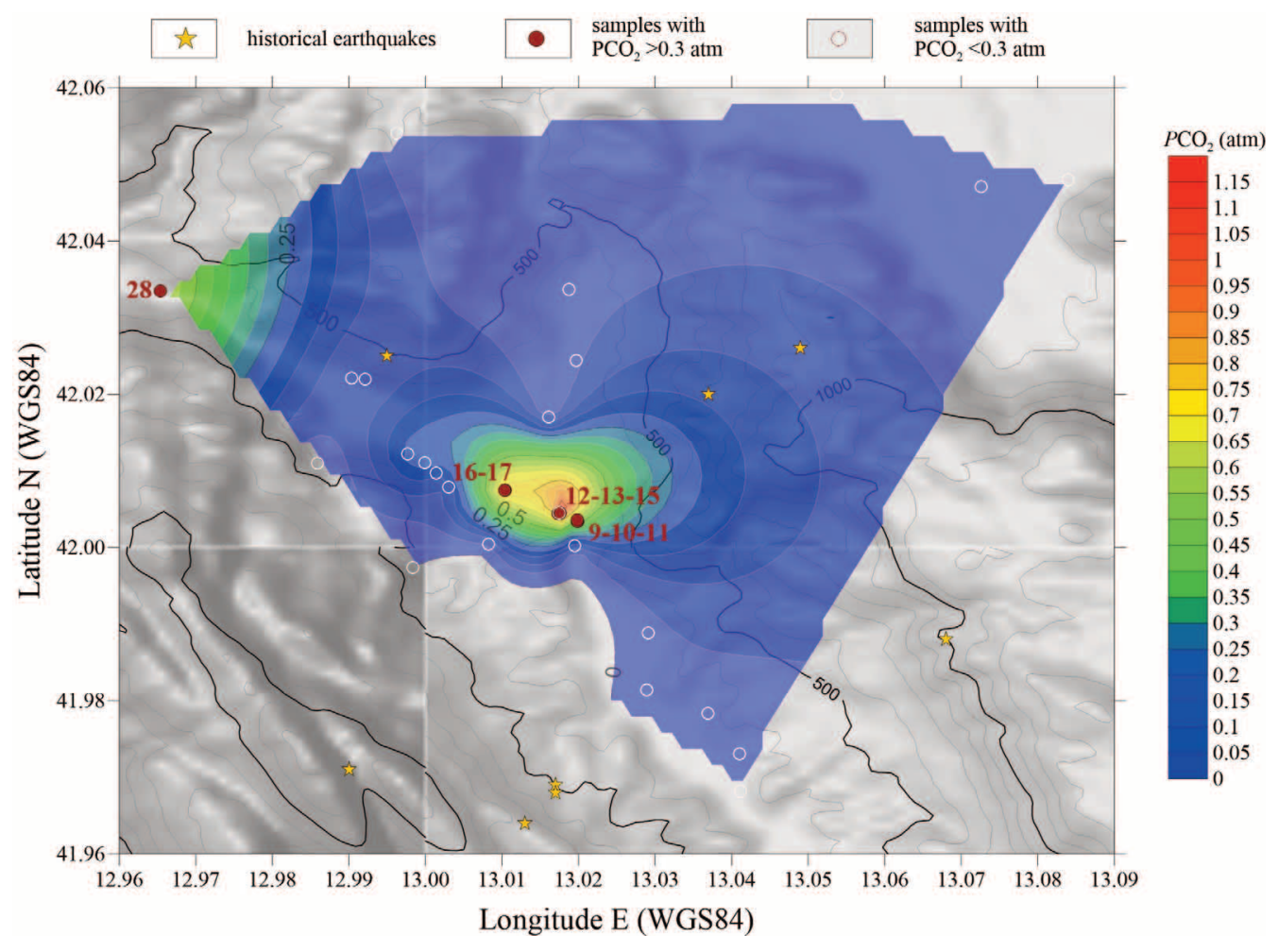

Figure 9. Map of dissolved $\mathrm{PCO}_{2}$ and location of historical earthquakes (yellow stars) taken from the "Catalogo Parametrico dei Terremoti Italiani, versione CPTI15, [Rovida, et al., 2011]. Some low $\mathrm{PCO}_{2}$ samples fall outside the SE limits of the map.

Chemical compositions of groundwater, concentrations of $\mathrm{CH}_{4}$ and $\mathrm{CO}_{2}$, and the isotopic signature of carbon dioxide are coherent in suggesting that, in a general scenario typical of a karst environment, there is a local anomaly due to the interaction with hydrothermal fluids rising from depth, mainly composed of non-organic $\mathrm{CO}_{2}, \mathrm{CH}_{4}$, and $\mathrm{H}_{2} \mathrm{~S}$. Contrary to what observed as a general character of karst aquifers in Central Italy, where travertine deposits are often associated to deep $\mathrm{CO}_{2}$ [Madonia, et al., 2020], travertine at spring 35 (Figure 10a) seems to be related to a simple loss of organic carbon dioxide. In fact, this spring shows low $\mathrm{PCO}_{2}$ with an organic carbon isotopic signature. Conversely, a marked hydrothermal nature is found in site 17 (Figure 10b), a pool with flocculating sulphur and bubbling gases.

The isotopic signature of oxygen and deuterium of groundwater samples collected in 2019 further remarks the gaseous nature of the hydrothermal fluids interacting with the shallow, meteoric component of the aquifers, excluding a mixing with groundwater of deeper origin. In the $\delta^{18} \mathrm{O}$ vs $\delta^{2} \mathrm{H}$ diagram (Figure 8) the points related to the analysed samples occupy the same area of other reference values [Madonia, et al., 2020] for Central Italy, well fitted by the local groundwater line [Celico et al., 1984] but above the line representative of local rainfalls (LMWL) [Longinelli and Selmo, 2003].

A mixing with hydrothermal groundwater, richer in ${ }^{18} \mathrm{O}$ and ${ }^{2} \mathrm{H}$, would shift the points in the lower right direction with respect the LMWL, e.g. toward the composition evidenced in yellow in Figure 8. Since we observe the opposite behaviour, a mixing between the meteoric recharge and deep, hydrothermal groundwater can be excluded. This fact is further remarked by the negative $\delta^{18} \mathrm{O}$ values observed in springs no. 15 and 17 , which are those with the best evidence of a chemical composition modified by a hydrothermal contribution. Their isotopic composition is quite similar to that one of spring no. 36, which receives a direct meteoric recharge from the highest elevated areas of Mts. Simbruini, as later discussed.

The oxygen isotopic signature of the collected groundwaters is helpful for reconstructing the residence time of the studied aquifers. In Figure 11, the elevation of the sampled sites is plotted against their $\delta^{18} \mathrm{O}$, together with two lines, both with slope of $-0.0013 \delta \% \mathrm{~m}^{-1}$, which represent the vertical variation of the yearly weighted average (intercept at $-5.9 \delta \%$ ) and of the winter average (intercept at $-8 \delta \%$ ) isotopic composition of rainfall for Central Italy [Longinelli and Selmo, 2003]. 

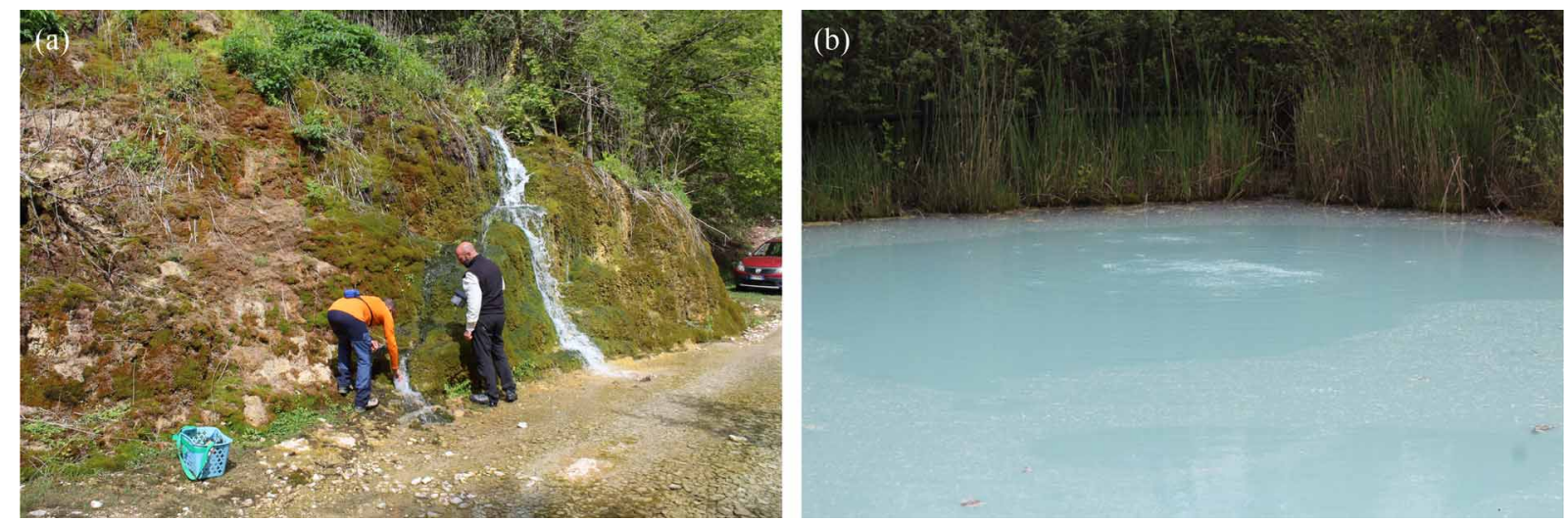

Figure 10. a) The Cardellino spring (site 35) forming a travertine deposit; b) the Lauriella pool (site 17) showing flocculating sulfur and bubbling gases.

Since the lowest point of an aquifer is its spilling point (spring), in the graph of Figure 11 a vertical line traced upward from the spring elevation should intersect the vertical isotopic gradient line in a point corresponding to the average elevation of the recharge area, inferred by the isotopic composition of rainfalls. This is true under the condition that the measured isotopic composition is equal to the yearly weighted average value of that spring.

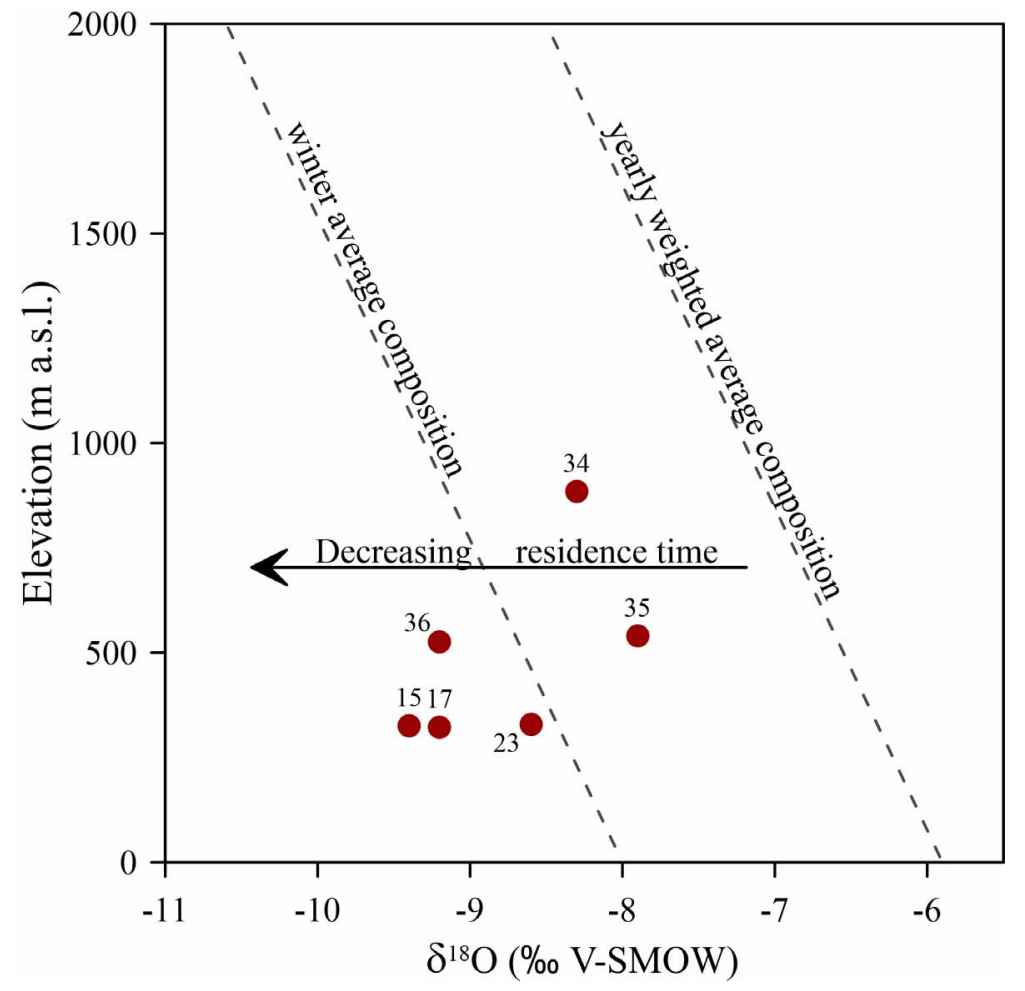

Figure 11. Plot of $\delta^{18} \mathrm{O}$ vs elevation of 2019 groundwater samples, with vertical isotopic gradients for Central Italy (dashed lines) after [Longinelli and Selmo, 2003]. Two different gradients are represented: one calculated using the yearly average isotopic composition, weighted on rainfall amounts, and the other one using only winter precipitations.

As shown in the graph, only points 34 and 35 exhibit an isotopic composition compatible with this condition, whereas the positions of all the other points imply shorter residence times. In particular, the values measured in 15 , 


\section{Marianna Cangemi et al.}

17, 23 and 36 suggest that at the time of sampling (May) the springs were releasing water infiltrated during the late autumn-winter months. A fast circulation, with mean residence times shorter than 1 year, is a typical feature of karst systems, where groundwater moves through wide conduits. This condition is remarked by field observations at site no. 36, a karst resurgence ("Inferniglio" spring) located at an elevation of $526 \mathrm{~m}$ a.s.l., draining a rock volume extended up to an altitude of $1550 \mathrm{~m}$ a.s.l. (Campo dell'Osso plateau), characterized by high mean flow rates $\left(2.0 \mathrm{~m}^{3} \mathrm{~s}^{-1}\right)$ modulated by huge variations following heavy showers. Small deposits of volcanic particles are found at this outlet, whose origin is the erosion and the following transportation as suspended solids of a thin (few tens of centimeters) pyroclastic level (alternations of volcanic sands rich in pyroxene phenocrysts and clayey ash) outcropping at Campo dell'Osso plateau. These deposits, found after flooding events, indicate that rainwater infiltrating at high elevations rapidly moves toward the basal aquifer through karst discontinuities, as large as to grant enough energy to maintain in suspension the volcanic particles.

Besides the Colli Albani volcanic complex, volcanic phenomena are reported in the area bordering the study zone, i.e. the two necks of Vicovaro and Mt. Autore to the north, and the lava effusions to the south-east [Accordi and Angelucci, 1962]. These findings confirm the existence of vertical discontinuities that favour either the hydrothermal fluid upraise and the rapid development of vertical karst conduits, which justify the short residence time of most of these waters.

\section{Conclusions}

The geochemical study carried out on 36 samples of Mts. Simbruini groundwaters, mostly from the Aniene valley, classifies these waters as bicarbonate alkaline-earth type hosted in a carbonate aquifer. The capture of these waters contributes significantly to the water supply of Rome city. The main process controlling the water chemical composition is water-rock interaction with dissolution driven by $\mathrm{CO}_{2}$ of carbonates, as calcite, magnesium calcite and dolomite. Probability plots of $\mathrm{HCO}_{3}^{-}, \sum$ cations and $\mathrm{Ca}^{2+}+\mathrm{Mg}^{2+}$ indicate the presence of four water populations, the less represented of which ( 9 samples $=2 \%$ ) shows the highest $\mathrm{PCO}_{2}$ values $(>0.3 \mathrm{~atm})$. Most of the samples $(8$ out of 9) with anomalous content of dissolved $\mathrm{CO}_{2}$ are from springs located in the central part of the study area, whereas the ninth is from an old well at the NW extremity of it (Figure 9).

The $\delta^{18} \mathrm{O}$ isotopic composition of the water indicates, for most of the springs, a fast circulation typical of karst systems, with mean residence times shorter than 1 year.

A positive correlation between $\mathrm{PCO}_{2}$ and $\delta^{13} \mathrm{C}_{\mathrm{CO} 2}$ has been found in the six analyzed samples. Four samples have a very low $\mathrm{PCO}_{2}$ (from 0.006 to $0.012 \mathrm{~atm}$ ) and negative $\delta^{13} \mathrm{C}_{\mathrm{CO} 2}$ (from -15.49 to $-22.12 \%$ os. PDB); two samples from the central area have distinctly higher $\mathrm{PCO}_{2}(0.759$ and $1.57 \mathrm{~atm})$ and $\delta^{13} \mathrm{C}_{\mathrm{CO} 2}$ values (1.65 and 2.63) similar to that of Colli Albani magmatic gas [Madonia, et al., 2020]. Therefore, geochemical data indicate that in the central part of the study area deep originated $\mathrm{CO}_{2}$, uprising along fractures , fluxes the karst aquifer.

The absence of a ${ }^{18} \mathrm{O}$ isotopic shift in the analyzed samples suggests that there is no mixing between the meteoric recharge and deep hydrothermal groundwater, and that the hydrothermal contribution is limited to gaseous species of deep origin flushing shallow, meteoric aquifers.

\section{References}

Accordi, B. and A. Angelucci (1962). Un neck nel calcare cretacico di Monte Autore (Subiaco, Roma), Geologica Romana, 1, 289-296.

Andreas, W.H. and A. Hairigh (2008). ${ }^{18} \mathrm{O}$-Equilibration on Water, Fruit Juice and Wine Using Thermo Scientific GasBench II. Thermo Fisher Scientific, Brema.

Cangemi, M., M.G. Di Figlia, R. Favara, and M. Liotta (2020). $\mathrm{CO}_{2}$ degassing in Sicily (Central Mediterranean) as inferred from groundwater composition, Water, 12, 1959, doi:10.3390/w12071959.

Capasso, G., R. Favara, F. Grassa, S. Inguaggiato, and M. Longo (2005). On-line technique for preparing and measuring stable carbon isotope of total dissolved inorganic carbon in water samples ( $\left.\delta^{13} \mathrm{C}\right)$, Ann. Geophys., 48, $159-166$.

Capasso, G. and S. Inguaggiato (1998). A simple method for the determination of dissolved gases in natural waters. An application to thermal waters from Vulcano Island, Appl. Geochem, 13, 631-642. 
Capelli, G., L. Mastrolillo, R. Mazza, M. Petitta, T. Baldoni, F. Banzato D. Cascone, C. Di Salvo, and F. La Vigna (2012). Carta delle unità idrogeologiche della Regione Lazio, Foglio 2, 1:100.000.

Carapezza, M.L., M. Ranaldi, L. Tarchini, T. Ricci, and F. Barberi (2020). Origin and hazard of $\mathrm{CO}_{2}$ and $\mathrm{H}_{2} \mathrm{~S}$ emissions in the Lavinio-Tor Caldara zone (Metropolitan City of Rome Capital, Italy), J. Volcanol. Geotherm. Res., 402, 106985, doi:https://doi.org/10.1016/j.jvolgeores.2020.106985.

Carminati, E., S. Fabbi and M. Santantonio (2014). Slab bending, syn-subduction normal faulting, and out-ofsequence thrusting in the Central Appennines, Tectonics, 33, 530-551; doi:10.1002/2013TC003386.

Célico, P., R. Gonfiantini, M. Koizumi, and F. Mangano (1984). Environmental isotope studies of limestone aquifers in central Italy, In Isotope Hydrology, IAEA: Vienna, Austria, 173-192.

Chiodini, G., F. Frondini, D.M. Kerrick, J. Rogie, F. Parello, L. Peruzzi, and A.R. Zanzari (1999). Quantification of deep $\mathrm{CO}_{2}$ fluxes from Central Italy. Examples of carbon balance for regional aquifers and of soil diffuse degassing, Chem. Geol., 159, 205-222.

Craig, H. (1961). Isotopic variations in meteoric waters, Science, 133, 1702-1708.

Dondi, L.; Papetti, I. and Tedeschi, D (1966). Stratigrafia del pozzo Trevi 1 (Lazio), Geol. Rom., 5, 249-262.

Fabbi, S. (2016). Geology of the Northern Simbruini Mts. (Abruzzo - Italy), J. Maps, 12, 441-452, https://doi.org/10.1080/17445647.2016.1237899.

Kracht O. and A. Hilkert (2016). EA-IRMS: Fast and Precise Isotope Analysis of Liquids on a Delta V Isotope Ratio MS with a High Temperature Conversion Elemental Analyzer. Thermo Fisher Scientific, Brema.

Longinelli, A. and E. Selmo (2003). Isotopic composition of precipitation in Italy: a first overlap map, J. Hydrol., 270, $75-88$.

Madonia, P., M. Cangemi, Y. Oliveri, and C. Germani (2020). Hydrogeochemical characters of karst aquifers in central Italy and relationship with neotectonics, Water, 12, 1926, doi:10.3390/w12071926.

Parkhurst, D.L. and C.A.J. Appelo (2020). Description of input and examples for PHREEQC version 3-A computer program for speciation, batch-reaction, one-dimensional transport, and inverse geochemical calculations: U.S. Geological Survey Techniques and Methods, http://pubs.usgs.gov/tm/06/a43 (accessed 12/02/2020).

Percopo, C. (1998). Idrogeologia del medio e alto fiume Aniene. PhD Thesis. Università degli studi di Roma "La Sapienza (In Italian), 101, https://www.idrogeologiaquantitativa.it/?p=2635 \&lang=it.

Rovida, A., R. Camassi, P. Gasperini, and M. Stucchi (2011). Catalogo parametrico dei terremoti italiani, versione CPTI11, Istituto Nazionale di Geofisica e Vulcanologia, Milano.

Sinclair, A.J. (1974). Selection of threshold values in geochemical data using probability graphs, J. Geochem. Explor., 3, 129-149.

Società Speleologica Italiana (2002). Carta delle principali aree e sorgenti carsiche d'Italia. Erga Edizioni, Firenze.

Stevanovic', Z. (2015). Karst Aquifers - Characterization and Engineering, Springer, Cham, 687, doi:https://doi.org/10.1007/978-3-319-12850-4.

Stevanovic', Z. I. Jemcov, and S. Milanovic (2007). Management of karst aquifers in Serbia for water supply, Environ. Geol., 51, 743-748, doi:10.1007/s00254-006-0393-z.

Vinci, M. (1998). Idrogeologia e Chimismo delle acque sotterranee del medio Aniene: anno di osservazione 1996, Thesis for Geological Science degree, La Sapienza University, Rome.

Zhang, J., P.D. Quay, and D.O. Wilbur (1995). Carbon isotope fractionation during gas-water exchange and dissolution of $\mathrm{CO}_{2}$, Geoc. Cosm. Acta, 59, 107-114. 